OPEN ACCESS

Edited by: Wolfgang Schöfberger Johannes Kepler University of Linz, Austria

Reviewed by:

Andrew Ng Kay Lup, Xiamen University, Malaysia

Benjaram M. Reddy, Indian Institute of Chemical Technology (CSIR), Hyderabad

*Correspondence: Vidya Avasare vidya.avasare@gmail.com Sourav Pal

s.pal@iiserkol.ac.in

Received: 17 September 2021 Accepted: 11 October 2021 Published: 19 November 2021

Citation:

Parmar SV, Avasare V and Pal S (2021) Unraveling the Effect of Aromatic Groups in Mn(I)NNN Pincer Complexes on Carbon Dioxide Activation Using Density Functional Study.

Front. Chem. 9:778718. doi: 10.3389/fchem.2021.778718

\section{Unraveling the Effect of Aromatic Groups in Mn(I)NNN Pincer Complexes on Carbon Dioxide Activation Using Density Functional Study}

\author{
Saurabh Vinod Parmar ${ }^{1}$, Vidya Avasare ${ }^{1,2 *}$ and Sourav $\mathrm{Pal}^{2,3 *}$ \\ ${ }^{1}$ Department of Chemistry, Sir Parashurambhau College, Pune, India, ${ }^{2}$ Department of Chemistry, Ashoka University, Sonipat, \\ India, ${ }^{3}$ Indian Institute of Science Education and Research, Kolkata, India
}

Carbon dioxide utilization is necessary to reduce carbon footprint and also to synthesize valueadded chemicals. The transition metal pincer complexes are attractive catalysts for the hydrogenation of carbon dioxide to formic acid. There is a need to understand the factors affecting the catalytic performance of these pincer complexes through a structure-activity relationship study using computational methods. It is a well-established fact that aromatic functionalities offer stability and selectivity to transition metal catalysts. However, their impact on the performance of the catalysts is lesser known in the case of metal pincer complexes. Hence, it is necessary to investigate the catalytic performance of $\mathrm{Mn}(\mathrm{I}) \mathrm{NNN}$ pincer complexes with variably activated aromatic functionalities. In this context, 15 catalysts are designed by placing different types of aromatic rings at the pincer carbons and two terminal nitrogen of Mn(I)NNN pincer complexes. A benzene moiety, placed at $\mathrm{C} 2-\mathrm{C} 3$ carbons of Mn(I)NNN pincer complex with identical aromatic groups at the terminal nitrogen, is found to be most efficient toward $\mathrm{CO}_{2}$ hydrogenation than the rest of the catalysts. On the other hand, when $\mathrm{N}, \mathrm{N}$-dimethyl aniline is placed at C2-C3 carbons of Mn(I)NNN pincer complexes, then the catalytic performance is significantly decreased. Thus, the present study unravels the impact of aromatic groups in $\mathrm{Mn}(\mathrm{l})$ NNN pincer complexes toward the catalytic hydrogenation of carbon dioxide.

Keywords: Mn pincer complexes, carbon dioxide, hydrogenation, NNN pincer ligands, density functional theory

\section{INTRODUCTION}

The burning of fossil fuels continuously increases $\mathrm{CO}_{2}$ concentration in the atmosphere, leading to a substantial and negative impact on the world climate. About 33,890.8 million tons of $\mathrm{CO}_{2}$ was released into the atmosphere in 2018, and the global $\mathrm{CO}_{2}$ concentration in the atmosphere reached 407.65 (BP Statistical Review of World Energy, 2019; Global Monitoring Division, 2019) Nearly $\sim 35 \mathrm{GT}$ of $\mathrm{CO}_{2}$ is being added to the atmosphere per year, and there is a considerable gap between the amount of $\mathrm{CO}_{2}$ produced and utilized. Therefore, carbon dioxide utilization becomes a necessity to save the world from global warming. $\mathrm{CO}_{2}$ utilization would not only help to remove $\mathrm{CO}_{2}$ from the atmosphere but also helps to get alternate fuels and to reduce dependence on petrochemicals and, thus, restricts $\mathrm{CO}_{2}$ expulsion in the atmosphere (Centi and Perathoner, 2009; Balaraman et al., 2011). Apart from forming fuels from carbon dioxide, many synthetically useful chemicals are being synthesized from carbon dioxide (Aresta, 2010). The conversion of formic acid from carbon dioxide has manyfold benefits to the environment and economy. Formic acid is considered to be potential chemical hydrogen storage material because of its stability, nontoxicity, and easy accessibility 


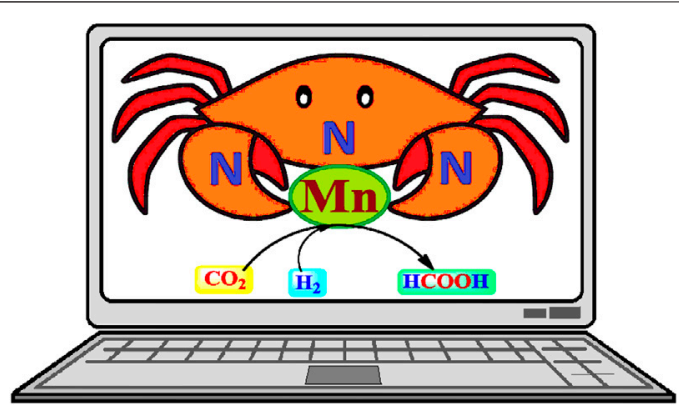

GRAPHICAL ABSTRACT | TOC for paper.

(Dörthe et al., 2016; Jörg et al., 2017; Miriam et al., 2019; Ganesh, 2014; Kassem et al., 2020). The global formic acid market is growing at a CAGR of $1.3 \%$, and it is expected to reach US\$828.1 million by 2025 due to its wide applications in agriculture, leather, textile, rubber, chemical and pharmaceuticals, and industries (https://dataintelo.com/report/formic-acid-market). Therefore, developing an energy-efficient and environmentally benign protocol to get formic acid from $\mathrm{CO}_{2}$ becomes significant.

In carbon dioxide activation and formation of formic acid or formate derivatives, the use of rhodium, ruthenium, and iridium pincer complexes have made remarkable progress in recent years (Wen, et al., 2021; Wang et al., 2013; Huff and Sanford, 2011, Wesselbaum et al., 2012; Kothandaraman et al., 2016; Wesselbaum et al., 2015; Campos et al., 2014). However, the high price and limited availability of these metals restrict their wide applications to an industrial scale. Therefore, the development of new catalytic technologies based on earth-abundant metals such as $\mathrm{Fe}, \mathrm{Mn}, \mathrm{Ni}$, and Co is of considerable interest (Figure 1) (Zell and Milstein, 2015; Furstner, 2016; Langer et al., 2011; Zhang et al., 2015; Ge et al., 2016; Choi and Lee., 2020; Curley et al., 2018). The transition metal pincer complexes of these earth-abundant metals are of particular importance due to their thermal stability, cost efficiency, and flexibility for modification. The flexibility in the modification could be useful to fine-tune structural and electronic properties of the metal pincer complexes to make them more reactive as well as more selective (Peris and Crabtree, 2018). In this context, Mn pincer complexes in catalytic carbon dioxide hydrogenation have seen much progress over a much shorter time (Bertini et al., 2017; Garbe et al., 2017; Kar et al., 2017). The PNP, PCP PNN pincer complexes have been commonly used to develop transition metal pincer complexes (Kumar et al., 2019; Bernskoetter and Hazari, 2017; Irina et al., 2016; Bertini et al., 2016; Jan et al., 2020). It is necessary to understand the donor-acceptor strength of the ligand during the rational ligand designing for new catalyst development. In all the cases, the metal-ligand interaction will depend highly on the choice of the transition metal, oxidation state, coordinating sites of the ligands, and the substituents on ligands. Steric bulk is also an extremely important aspect not only for enhancing the stability of the complexes but also for providing stereoselectivity (Garbe et al., 2019; Wen et al., 2021; Jessica et al., 2017). The NNN pincer ligands are of particular importance due to their accessibility, scalability, stability, and affordability. In the recent review, Crabtree mentioned that there is a necessity to explore transition metal NNN pincer complexes and to understand their catalytic performance (Peris and Crabtree, 2018). Herein, $15 \mathrm{Mn}(\mathrm{I}) \mathrm{NNN}$ pincer complexes are designed to understand steric and electronic factor ligands on the catalytic efficacy toward carbon dioxide hydrogenation (Figure 2). However, it would be difficult to understand the efficacy of these $15 \mathrm{Mn}(\mathrm{I}) \mathrm{NNN}$ complexes and also to throw light on the impact of aromatic and heterocyclic rings present in the NNN pincer ligands by using experimental methods. Therefore, the use of computational methods to assess a large number of complexes by evaluating the mechanistic pathway and energetics of the reaction is highly desirable.
Previous Work:

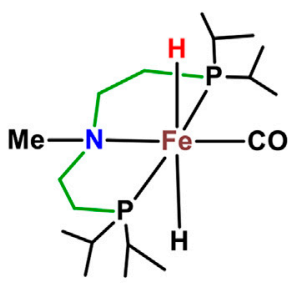

This work:

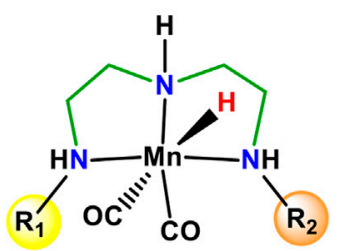

Hazari (2018)

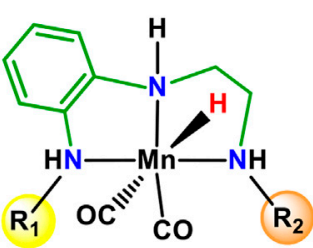

Lee (2020)<smiles>CC(C)P(c1ccccc1N1c2ccccc2[PH](C(C)C)(C(C)C)C1(C)C)P(C(C)C)C(C)C</smiles>

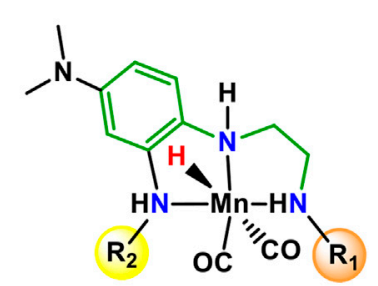

FIGURE 1 | Recently developed NNN pincer ligands with varying electron withdrawing and donating moieties. 


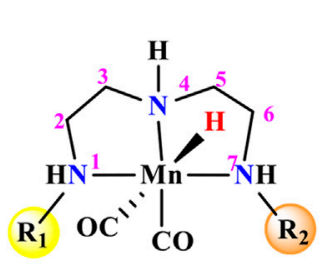

Group-1

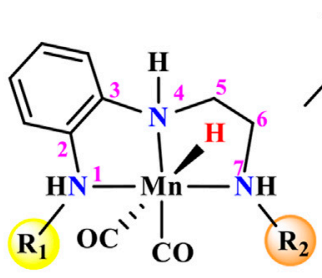

Group-2

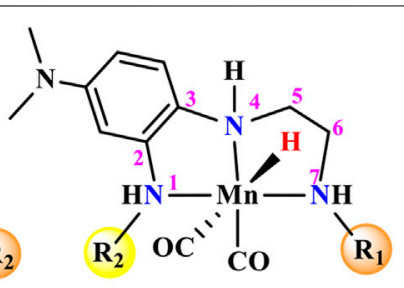

Group-3

$$
\begin{aligned}
& \text { 1a; } 2 \mathrm{a} ; 3 \mathrm{a} ; \mathrm{R}_{1}=\mathrm{R}_{2}=\mathrm{H} \\
& \text { 1b; } 2 \mathrm{~b} ; 3 \mathrm{~b} ; \mathrm{R}_{1}=\mathrm{R}_{2}=\mathrm{dma} \\
& \text { 1c; } 2 \mathrm{c} ; 3 \mathrm{c} ; \mathrm{R}_{1}=\mathrm{Py} \text { and } \mathrm{R}_{2}=\mathrm{dma} \\
& \text { 1d; } 2 \mathrm{~d} ; 3 \mathrm{~d} ; \mathrm{R}_{1}=\mathrm{Pym}_{\mathrm{md} \mathrm{R}_{2}=\mathrm{dma}} \\
& \text { 1e; } 2 \mathrm{e} ; 3 \mathrm{e} ; \mathrm{R}_{1}=\mathrm{R}_{2}=\text { pym }
\end{aligned}
$$

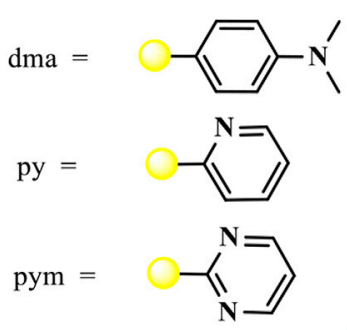

FIGURE 2 | Mn(I)NNN complexes designed for the computational study of the impact of aromatic substituents on carbon dioxide hydrogenation.

\section{COMPUTATIONAL DETAILS}

The Gaussian-16 program package was used to perform the computational calculations (Frisch et al., 2016). The metaGGA hybrid M06 functional with dispersion corrections without the imposition of any symmetry constraints were used to optimize reactants and intermediates (Zhao and Truhlar, 2008a). M06 is the accurate, economical functional for transition metals than B3LYP functional (Hehre et al., 1972). The SDD basis set was used for manganese, and Pople's 6-31G(d,p) basis set was used for all the main group elements (Hariharan and Pople, 1973; Hay and Wadt, 1985). All complexes were treated as neutral species to compute optimized energies. The ground states of intermediates and transition states were confirmed as singlets through the comparison with optimized high-spin analogs. All transition states exhibited a single imaginary frequency, corresponding to the eigenvector along the reaction path. Frequency analysis of all the stationary points was performed at the same level of theory to confirm stationary points as minima or first-order saddle points along with the reaction coordinate (Liu et al., 2012; Jain et al., 2018; Zhao and Truhlar, 2008b). Intrinsic reaction coordinates (IRCs) were carried out on the transition states to endorse that such structures were indeed connecting the two minima, reactant, and product (Fukui, 1970; Fukui, 1981). All the calculations presented in this work were performed in the presence of water (dielectric constant $=78.39$ ) using the integral equation formalism variant-like solvation model based on density (SMD) (Aleksandr et al., 2009; Aleksandr et al., 2009).

NBO analysis was carried out using the NBO 3.1 suite as implemented in Gaussian-16 (Foster and Weinhold, 1980; Reed et al., 1985; Reed and Weinhold, 1985; Glendening et al., 1987; Carpenter et al., 1988; Reed et al., 1988). The second-order perturbative estimation of donor-acceptor stabilization energy $\left(E_{s}\right)$ was calculated using the following equation,

$$
E_{s}=\Delta E_{i j}=q_{i} \frac{F_{i j}^{2}}{\Delta \varepsilon_{j i}}
$$

where $q_{i}$ is the donor orbital occupancy number, and $F_{i j}$ is the offdiagonal element of the Fock matrix in the $\mathrm{NBO}$ basis. $\Delta \varepsilon_{j i}=\varepsilon_{j}-\varepsilon_{i}$ is the orbital energy difference between the acceptor $(j)$ and donor $(i)$ NBO.

The solvent-corrected relative Gibbs free energies $(\Delta G)$ for the transition states and intermediate as well as overall activation Gibbs free energies $\left(\Delta \mathrm{G}^{\square}\right)$ for the catalytic cycle was calculated at 1 atm pressure and $298.15 \mathrm{~K}$ temperature. Visualization of all optimized structures was performed using the CYLview software (CYLview, 2020), and imaging of all NBO structures and orbitals was performed using the Chemcraft Visualization software (Chemcraft, 2021).

\section{CATALYST DESIGNING}

A large number of pincer catalysts have been developed for various catalytic applications. (Bernskoetter and Hazari, 2017; Irina et al., 2016; Garbe et al., 2019; Kumar et al., 2019; Kar et al., 2020; Wen et al., 2021). However, PNP and PCP pincer complexes have been studied mostly than NNN pincer complexes (Bernskoetter and Hazari, 2017; Bertini et al., 2016; Kar et al., 2019; Tang et al., 2019). Therefore, it is necessary to explore the efficacy of $\mathrm{Mn}(\mathrm{I}) \mathrm{NNN}$ pincer complexes toward the activation of carbon dioxide. In many instances, aromatic systems 


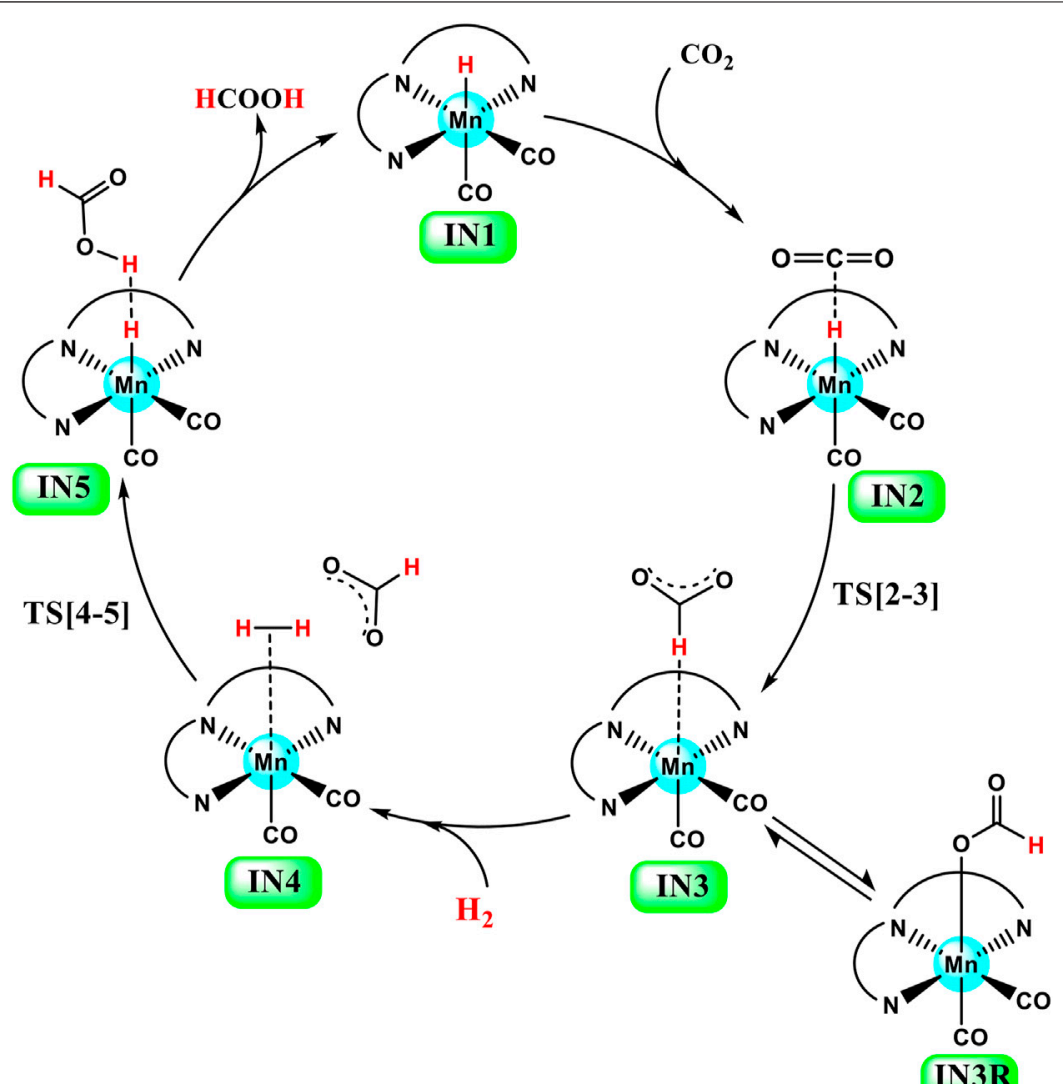

FIGURE 3 | General catalytic cycle of Mn(I)NNN-catalyzed hydrogenation of carbon dioxide to formic acid through the NC pathway for Groups 1, 2, and $\mathbf{3}$ catalysts.

are commonly used during the designing of metal pincer complexes with limited combinations (Figure 1) (Choi and Lee., 2020; Jessica et al., 2015; Talukdar et al., 2019). The aromatic systems are known to provide better thermal stability to the catalyst complex by offering steric bulk and hydrophobic groups to minimize the leaching of the metals. However, it is very important to understand the impact of the position and the nature of the aromatic rings present in the pincer complexes on their catalytic performances. It would be impossible to study all these parameters using any experimental study, and hence, the DFT (density functional theory) would play an important role to throw light on the effect of aromatic rings on the efficacy of the catalysts. Herein, 15 catalysts were designed by changing the position and reactivity of the aromatic ring attached to pincer ligands. These 15 catalysts were further studied to understand the impact of the position and nature of the aromatic rings on carbon dioxide hydrogenation (Figure 2). The computationally designed catalysts are classified into three groups: 1) Group 1: No aromatic ring is placed on pincer ring carbons. 2) Group 2: The benzene ring is inserted at the $\mathrm{C} 2-\mathrm{C} 3$ carbons of the pincer ring. 3) Group 3: The $\mathrm{N}, \mathrm{N}$-dimethyl aniline ring is inserted at the $\mathrm{C} 2-\mathrm{C} 3$ carbons of the pincer ring in such a way that the $\mathrm{N}, \mathrm{N}$-dimethyl group is para to the C3 nitrogen. All three groups are further subdivided into $\mathbf{a}, \mathbf{b}, \mathbf{c}, \mathbf{d}$, and e classes based on the substituents attached to the terminal nitrogens of the pincer ligands. The hydrogens attached to both the terminal nitrogens are replaced with differently activated aromatic rings in all the three groups like $\mathrm{N}, \mathrm{N}$-dimethyl aniline, pyridine, and pyrimidine (Figure 2). Catalysts 1a, 2a, and 3a contain all unsubstituted pincer nitrogen. The hydrogens of both the terminal nitrogen are replaced by an electron-donating group, $\mathrm{N}, \mathrm{N}$-dimethyl aniline, in $\mathbf{1 b}, \mathbf{2} \mathbf{b}$, and $\mathbf{3 b}$ catalysts, whereas catalysts $1 c, 2 c$, and $3 c$ contain pyridine and N,N-dimethyl aniline groups attached to both the terminal nitrogen of the $\mathrm{Mn}(\mathrm{I}) \mathrm{NNN}$ pincer complex. Catalysts 1d, 2d, and $\mathbf{3 d}$ are designed to have pyrimidine and N,N-dimethyl aniline groups attached to each terminal nitrogen of the pincer complexes. The two strong electrons withdrawing the pyrimidine groups are attached to the $\mathrm{Mn}(\mathrm{I}) \mathrm{NNN}$ pincer ring nitrogen in catalysts 1e, 2e, and 3e (Figure 2). All these $15 \mathrm{Mn}(\mathrm{I}) \mathrm{NNN}$ pincer complexes are further used to explore their catalytic performance toward carbon dioxide hydrogenation (Figure 3).

\section{RESULT AND DISCUSSION}

\section{Hydrogenation of Carbon Dioxide to Formic Acid Catalyzed by Group 1 Catalysts, 1a-1e}

Catalysts 1a-1e are designed to explore the impact of donating and withdrawing groups on the catalytic performance in the 


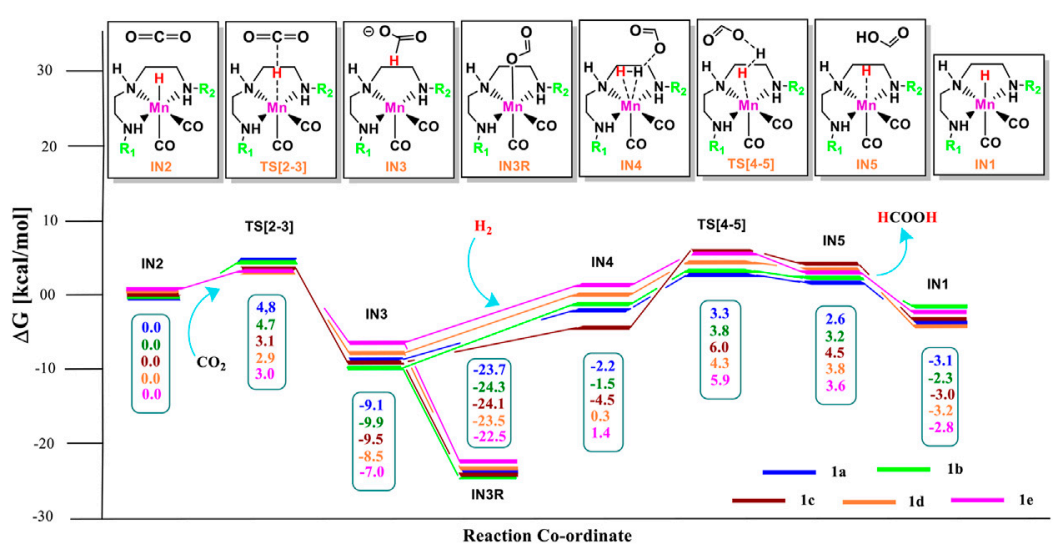

FIGURE 4 | Solvent-corrected relative Gibbs free energy profile for Mn(I)NNN-catalyzed formation of formic acid through the NC pathway for catalysts 1a-1e. Calculations were carried out at the M06/6-31G(d,p)-SDD(Mn), $\operatorname{SMD}\left(\mathrm{H}_{2} \mathrm{O}\right)$ level of theory.

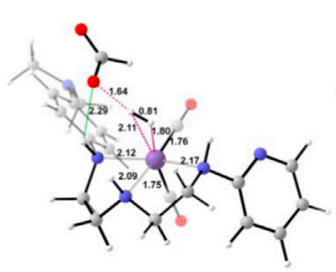

1c

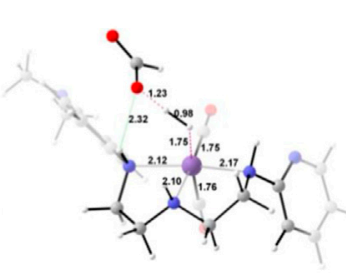

1c

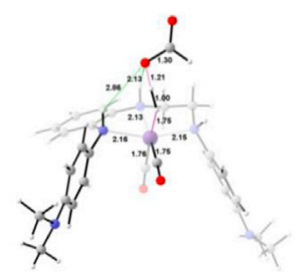

1b

IN4 (-4.5 kcal $/ \mathrm{mol})$

TS $[4-5](6.0 \mathrm{kcal} / \mathrm{mol})$

TS $[4-5](3.8 \mathrm{kcal} / \mathrm{mol})$

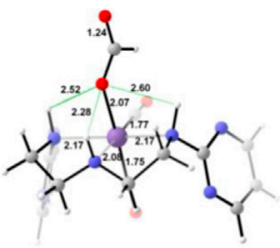

$1 \mathrm{e}$

IN3R (-22.5 kcal)

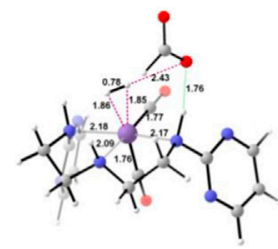

1e

IN4 (1.4 kcal/mol)

FIGURE 5 | The optimized geometries of the intermediates in the formation of formic acid from carbon dioxide. The bond lengths are in $\AA$, and the relative Gibbs free energies are in parentheses (Figures are shown in Supplementary Data Sheet $\mathbf{S} \mathbf{1}$ for all the optimized geometries of all the transition states and intermediates).

absence of any aromatic rings on the pincer ring carbons toward $\mathrm{CO}_{2}$ hydrogenation (Figure 2). The intermediate IN2 is obtained after the addition of $\mathrm{CO}_{2}$ to the active catalyst complex IN1 of the catalysts 1a-1e. The relative Gibbs free energies of the transition state and the intermediate states are calculated by considering the relative Gibbs free energy of the IN2 as $0.0 \mathrm{kcal} / \mathrm{mol}$ (Figure 4). The IN2 is further converted into the IN3 by transferring the hydride from the Mn center to the carbon dioxide carbon through the transition state TS[2-3].

The relative Gibbs free energies for the TS[2-3] are $\sim 3.0 \mathrm{kcal} /$ mol for the catalyst complexes 1c, 1 d, and $1 \mathrm{e}$ and $\sim 4.8 \mathrm{kcal} / \mathrm{mol}$ for the catalyst complexes 1a and $\mathbf{1 b}$. The IN3 of all three catalysts groups are stabilized with the relative Gibbs free energy of approximately $\sim-7.0$ to $-10.0 \mathrm{kcal} / \mathrm{mol}$. The relative Gibbs free energy of IN3 is minimum for $\mathbf{1} \mathbf{b}(-9.9 \mathrm{kcal} / \mathrm{mol})$ and maximum for 1 e $(-7.0 \mathrm{kcal} / \mathrm{mol})$. The IN3 further isomerizes to the IN3R $(-22.5$ to $-24.3 \mathrm{kcal} / \mathrm{mol})$ by forming an $\mathrm{Mn}-\mathrm{OCHO}$ bond. This is the most stable state TDI (Turn-over Determining Intermediate), and hence, it is also a rate-determining state of the reaction. The IN3R again isomerizes to IN3 with an energy barrier of $\sim 15.0 \mathrm{kcal} / \mathrm{mol}$, and then, the protonation takes place. The hydrogen molecule adds to IN3 to provide the IN4 comprising formic acid. The relative Gibbs free energy of the IN4 is minimum for $1 \mathrm{c}(-4.5 \mathrm{kcal} / \mathrm{mol})$ and maximum for $1 \mathrm{e}$ $(1.4 \mathrm{kcal} / \mathrm{mol})$ (Figure 5).

Interestingly, we found that in Group 1, the catalyst with a shorter $\mathrm{Mn}-\mathrm{N}(\mathbf{1 a}, \mathrm{Mn}-\mathrm{N}=2.13 \AA$ ) distance performs better than the catalyst with a longer $\mathrm{Mn}-\mathrm{N}$ bond (1e, 


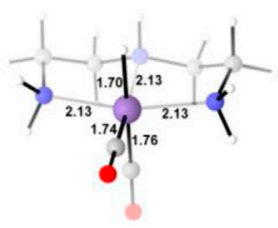

$1 \mathrm{a}$

IN1 (-3.1 kcal $/ \mathrm{mol})$

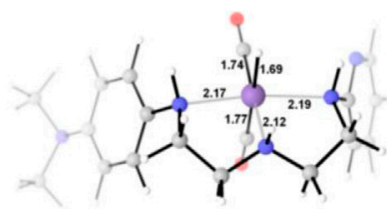

$1 c$

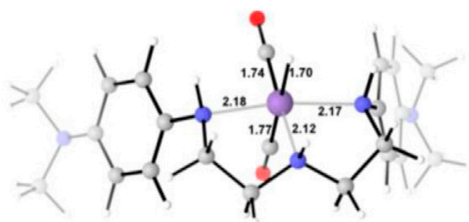

$1 b$

IN1 (-3.0 kcal/mol)

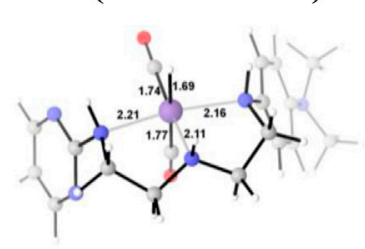

1d

\section{IN1 (-3.2 kcal $/ \mathrm{mol})$}

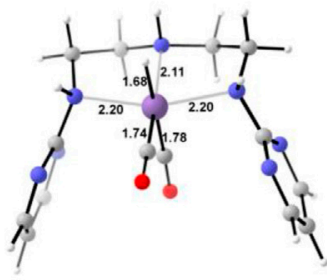

1e

\section{IN1 (-2.7 kcal/mol)}

FIGURE 6 | The optimized geometries of the Group 1 IN1 catalysts. The bond lengths are in $\AA$, and relative Gibbs free energies are in parentheses (The optimized geometries of all the transition states and intermediates are disclosed in Supplementary Data Sheet S1).

$\mathrm{Mn}-\mathrm{N}=2.20 \AA$ ) distance (Figure 6). However, there is no significant change in the $\mathrm{Mn}-\mathrm{N}$ bond distance during the catalytic reaction. The presence of a strong $\mathrm{H}$-bond $\left(\mathrm{HCOO}-\mathrm{H}_{2}=1.64 \AA\right)$ in $\mathbf{1 c}$ than in $\mathbf{1 e}\left(\mathrm{HCOO}-\mathrm{H}_{2}=2.43 \AA\right)$ lowers the relative Gibbs free energy in $1 \mathrm{c}(-4.5 \mathrm{kcal} / \mathrm{mol})$ than $1 \mathrm{e}$ $(1.36 \mathrm{kcal} / \mathrm{mol})$ in IN4. However, TS[4-5] of $\mathbf{1 c}$ is found to have higher Gibbs free energy than $\mathbf{1 b}$, due to strong $\mathrm{H}_{2}$ polarization and strong bond-forming interactions in $\mathbf{1 b}(1.00 \AA)$ than in $\mathbf{1 c}$ (0.98 $\AA$ ).

A similar dihydrogen polarization is found to be efficient in the $\mathrm{M}-\mathrm{H}_{2} \sigma$-complex of $1 \mathrm{c}(0.81 \AA)$ than in $1 \mathrm{e}(0.78 \AA)$. The IN4 is further converted into IN5, the regenerated catalyst and formic acid complex through the TS[4-5] with the relative Gibbs free energy of $3.3-6.0 \mathrm{kcal} / \mathrm{mol}$ for all the catalysts. However, the activation energy barrier for this step is the lowest for $1 \mathrm{a}(3.3 \mathrm{kcal} / \mathrm{mol})$ and the highest for $1 \mathbf{c}$ $(6.0 \mathrm{kcal} / \mathrm{mol})$. In this entire mechanism, the dihydrogen dissociation and catalyst regeneration steps are more energy demanding by $1-3 \mathrm{kcal} / \mathrm{mol}$ than the hydride transfer transition state for the catalyst complexes 1c, 1d, and $\mathbf{1 e}$. On the other hand, the catalysts complexes $\mathbf{1 a}$ and $\mathbf{1 b}$ show facile protonation via dihydrogen polarization than the
TABLE 1 | Catalytic performance of Group 1 catalyst, 1a-1e.

Catalyst group 1 Activation energy $\left(\Delta G^{\ddagger}\right)(\mathrm{kcal} / \mathrm{mol})$

$\begin{array}{ll}1 a & 23.9 \\ 1 b & 25.8 \\ 1 c & 27.1 \\ 1 d & 24.6 \\ 1 e & 25.7\end{array}$

hydride transfer from the Mn center to carbon dioxide. In overall $\mathrm{CO}_{2}$ to formic acid formation, catalysts $\mathbf{1 a}$ and $\mathbf{1 d}$ have almost the same catalytic efficiency as the rest of the catalysts with $\Delta \mathrm{G}^{\square}$ of 23.9 and $24.6 \mathrm{kcal} / \mathrm{mol}$ (Table 1), whereas catalyst complex $\mathbf{1 c}$ is most sluggish toward carbon dioxide hydrogenation. This indicates that unsubstituted carbon centers of $\mathrm{Mn}(\mathrm{I}) \mathrm{NNN}$ with unsubstituted nitrogen pincer ligands of Group 1 show better catalytic performance than the one with electronwithdrawing groups. The donating groups and moderate withdrawing groups at terminal nitrogen make $\mathbf{1 b}$ and $\mathbf{1 c}$ catalysts less reactive than the Mn(I)NNN complex 1a and 


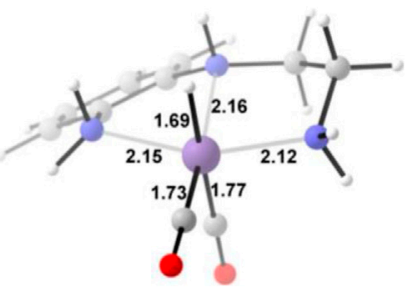

2a

IN1 (-4.1 kcal/mol)

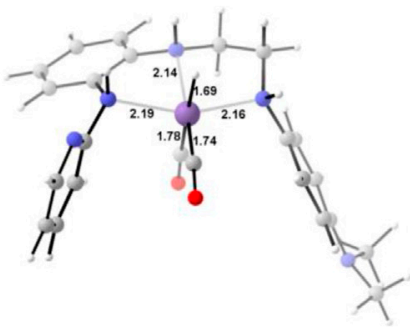

2c

IN1 (-3.1 kcal/mol)

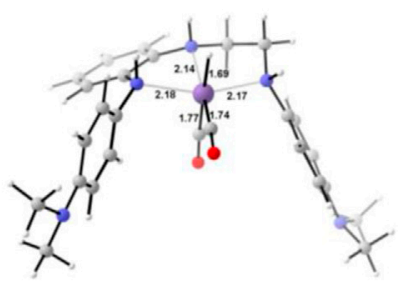

2b

IN1 (-6.3 kcal/mol)

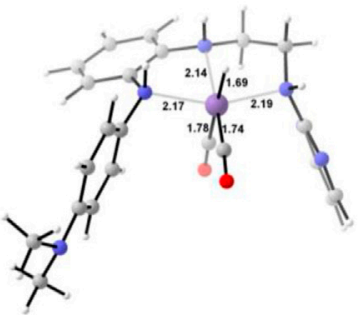

2d

IN1 (-3.5 kcal/mol)

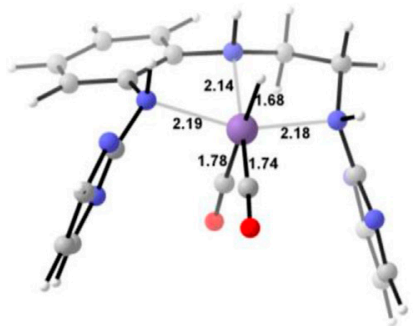

$2 \mathrm{e}$

IN1 $(-4.3 \mathrm{kcal} / \mathrm{mol})$

FIGURE 7 | The optimized geometries of the Group 2 IN1 catalysts. The bond lengths are in $\AA$, and relative Gibbs free energies are in parentheses (The optimized geometries of all the transition states and intermediates are disclosed in Supplementary Data Sheet S1).

1d. However, there is no drastic change in the reactivity when we change the $\mathrm{N}$ substituents in Group $1 \mathrm{Mn}(\mathrm{I}) \mathrm{NNN}$ pincer complexes.

\section{Hydrogenation of carbon dioxide to formic acid catalyzed by Group 2 catalysts $2 a-2 e$}

The unsubstituted pincer ring carbons provided exciting results; therefore, we decided to investigate the effect of aromatic substituents of the pincer carbons ( $\mathrm{C} 2$ and $\mathrm{C} 3$ ) on the catalytic performance (Curley et al., 2018; Kumar et al., 2019; Luca et al., 2020) (Figure 2). Herein, C2 and C3 carbons of catalysts 1a-1e are used to attach the unsubstituted aromatic ring to form the new pincer complexes 2a-2e (Figure 7). After the addition of carbon dioxide to these pincer complexes, IN2 is formed. The relative Gibbs free energy of the IN2 is considered as $0.0 \mathrm{kcal} / \mathrm{mol}$ to calculate the relative Gibbs free energies of the transition state and the intermediate states (Figure 8). The intermediate IN2 converts into the IN3 through the transition state TS[2-3]. The activation energy barrier for the TS[2-3] is found to be maximum for catalyst $2 \mathbf{b}(4.3 \mathrm{kcal} / \mathrm{mol})$ and minimum for catalyst $2 \mathrm{e}(1.9 \mathrm{kcal} / \mathrm{mol})$. The TS[2-3] $(1.9 \mathrm{kcal} / \mathrm{mol})$ has the lowest relative Gibbs free energy among all the Group 2 catalysts. This could be due to a strong $\mathrm{H}$-bond $[\mathrm{N}(1) \mathrm{H} . . . \mathrm{OCO}=2.7 \AA, \mathrm{N}(4) \mathrm{H} . . \mathrm{OCO}=2.3 \AA$, and $\mathrm{N}(7) \quad \mathrm{H} . . \mathrm{OCO}=2.9 \AA]$ among the Group 2 catalysts (Figure 9). The IN3 of $\mathbf{2 a}(-11.2 \mathrm{kcal} / \mathrm{mol})$ is the most stable, and $\mathbf{2 b}(-8.1 \mathrm{kcal} / \mathrm{mol})$ is less stable among all the catalysts. It has been reported in papers that IN3 isomerizes to a more stable metal formate intermediate, IN3R (Boodsarin et al., 2018; Kumar et al., 2019). Herein, all the IN3R intermediates are stabilized by three strong H-bonds with a relative Gibbs free energy of $\sim-24.0$ to $-27.0 \mathrm{kcal} / \mathrm{mol}$ (All energies are added in the table in Supplementary Data Sheet S1). However, strong H-bonds [N(1) H. . . OCHO = 2.26, $\mathrm{N}(4) \quad \mathrm{H} . . \mathrm{OCHO}=2.28 \AA$, and $\mathrm{N}(7) \mathrm{H} . . \mathrm{OCHO}=1.93 \AA$ ] stabilize the IN3R of catalyst 2d more effectively than the rest of the catalysts (Figure 9). The 


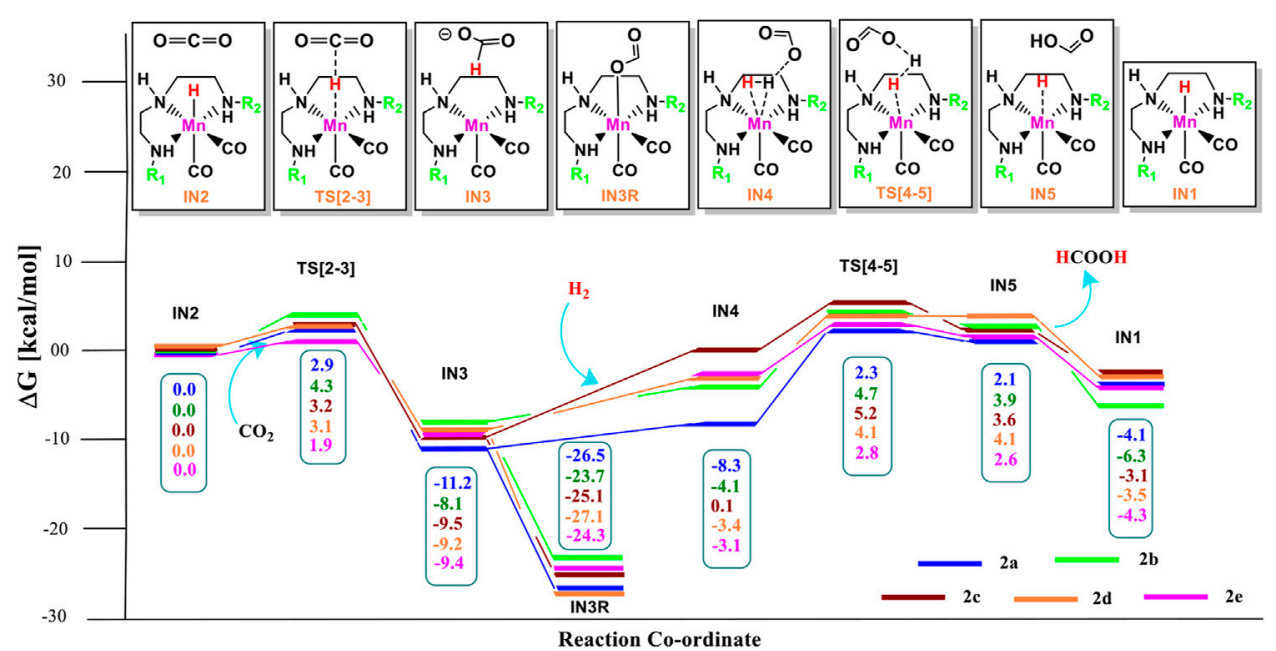

FIGURE 8 | Solvent-corrected relative Gibbs free energy profile for Mn(I)NNN-catalyzed formation of formic acid through the NC pathway for catalysts $\mathbf{2 a - 2 e . ~}$ Calculations were carried out at the M06/6-31G(d,p)-SDD(Mn), SMD( $\left.\mathrm{H}_{2} \mathrm{O}\right)$ level of theory.

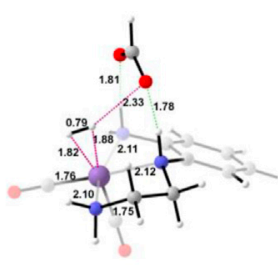

$2 \mathbf{a}$

IN4 (-8.3 kCal/mol)

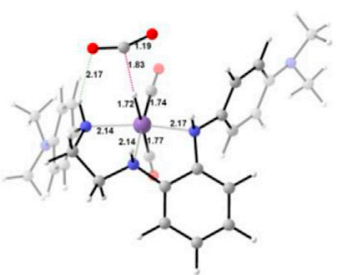

2b

TS[2-3] (4.33 kCal/mol)

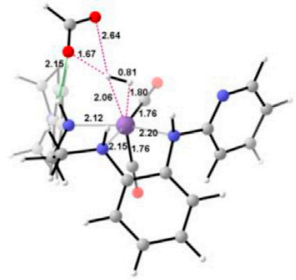

2c

IN4 (0.1 kCal/mol)

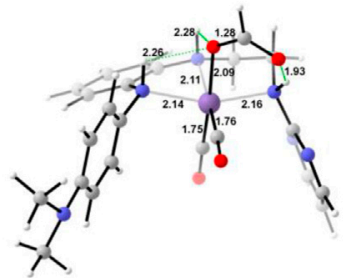

2d

IN3R (-27.1 kCal/mol)

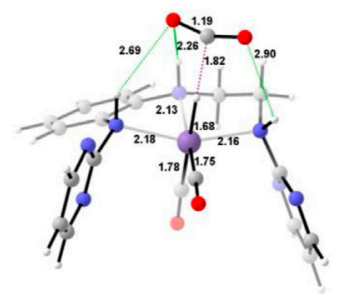

$2 \mathrm{e}$

TS[2-3] (1.9 kCal/mol)

FIGURE 9| The optimized geometries of the transition state in the formation of formic acid from carbon dioxide for catalysts $\mathbf{2 a - 2 e . ~ T h e ~ b o n d ~ l e n g t h s ~ a r e ~ i n ~} \AA$, and relative Gibbs free energies are in parentheses (Figures are shown in Supplementary Data Sheet S1 for all the optimized geometries of all the transition states and intermediates).

isomerization energy barrier for IN3R to IN3 is $\sim 15 \mathrm{kcal} / \mathrm{mol}$ for all the catalysts except $\mathbf{2 d}(18.0 \mathrm{kcal} / \mathrm{mol})$. When IN3R changes to IN3, then the hydrogen molecule adds to the IN3 to provide the intermediate IN4. In the IN4, there is an increase in the Gibbs free energy by $2-9 \mathrm{kcal} / \mathrm{mol}$ than IN3.

In the $\mathrm{Mn}-\mathrm{H}_{2} \sigma$-complex, the IN4 of catalyst $2 \mathbf{a}$ is most stable $(-8.3 \mathrm{kcal} / \mathrm{mol})$, whereas $2 \mathrm{c}$ is the least stable $(0.1 \mathrm{kcal} / \mathrm{mol})$ (Figure 9) among all the catalysts. The presence of stronger H-bonds $\quad[\mathrm{N}(1) \quad \mathrm{H} . \mathrm{OCCHO}=1.8 \AA \quad$ and $\mathrm{N}(4)$
H. . . OCHO $=1.78 \AA]$ offer better stability than all the catalysts ( $\sim 0$ to $-4 \mathrm{kcal} / \mathrm{mol})$. The IN4 of $2 \mathbf{a}$ shows an $\mathrm{Mn}-\mathrm{H}_{2} \sigma$-complex with an $\mathrm{Mn}$ center, and the remaining catalysts show a distorted Mn$\mathrm{H}_{2} \sigma$-complex, where one $\mathrm{Mn}-\mathrm{H}_{\mathrm{a}}(1.88 \AA)$ is longer than the other $\mathrm{Mn}-\mathrm{H}_{\mathrm{b}}(1.82 \AA)$ bond (Structure in Supplementary Data Sheet S1). These distortions in the $\mathrm{Mn}-\mathrm{H}$ bond could be due to strong dihydrogen polarization. The IN4 converts into IN5 through the TS [4-5], where the strong dissociation of a dihydrogen bond is observed in all the catalysts. The H-bond stabilizes the TS[4-5] 
TABLE 2 | Catalytic performance of Group 2 catalyst, 2a-2e.

\section{Catalyst group 2}

$\begin{array}{ll}2 a & 24.7 \\ 2 b & 22.1 \\ 2 c & 27.2 \\ 2 d & 27.7 \\ 2 e & 22.8\end{array}$

with the relative Gibbs free energy of 2.0 to $5.0 \mathrm{kcal} / \mathrm{mol}$. The IN5 contains the product, formic acid, and the regenerated catalyst complex. The IN5 further expels formic acid and provides regenerated catalysts, $\mathbf{2 a}-\mathbf{2 e}$. The $\Delta \mathrm{G}$ for the entire catalytic reaction is found to be minimum for catalysts $2 \mathbf{b}(22.1 \mathrm{kcal} /$ $\mathrm{mol})$ and $2 \mathrm{e}(22.8 \mathrm{kcal} / \mathrm{mol})$ and maximum for catalysts $2 \mathrm{c}$ $(27.2 \mathrm{kcal} / \mathrm{mol})$ and $2 \mathrm{~d}(27.7 \mathrm{kcal} / \mathrm{mol})$ (Table 2). This indicates that in Group 2, catalysts show better catalytic performance when both the terminal nitrogen are attached to either electron-donating groups, N,N-dimethyl aniline, or strong electron-withdrawing groups, pyrimidine. On the other hand, the catalytic performance slows down when these two terminal nitrogens carry mixed electron-withdrawing and donation groups $\mathbf{2 a}$ and 2c. However, catalyst 2a with an unsubstituted terminal nitrogen shows average performance toward carbon dioxide hydrogenation.

\section{Hydrogenation of carbon dioxide to formic acid catalyzed by Group 3 catalysts, 3a-3e} The unsubstituted Group 1, as well as benzene, substituted Group 2 manganese pincer complexes provided a deeper insight into their catalytic performances toward carbon dioxide hydrogenation reaction. Therefore, we also investigated the effect of the activated aromatic ring by placing N,N-dimethyl aniline at the $\mathrm{C} 2-\mathrm{C} 3$ of the pincer ligands of the $\mathrm{Mn}(\mathrm{I}) \mathrm{NNN}$ complex in Group 3 (Figures 2 and 10) (Smith et al., 2018). Complexes $\mathbf{3 a}-\mathbf{3 e}$ are designed to understand the effect of $\mathrm{Mn}(\mathrm{I}) \mathrm{NNN}$ complexes on carbon dioxide hydrogenation. After the addition of carbon dioxide to these pincer complexes, the IN2 is formed. The relative Gibbs free energy of the IN4 is considered as $0.0 \mathrm{kcal} / \mathrm{mol}$ to calculate the relative Gibbs free energies of the transition and the intermediate states (Figure 11). The IN2 converts into the IN3 through the transition state TS[2-3]. The

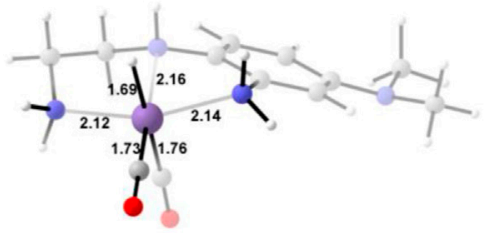

3a

IN1 (-2.1 kcal/mol)

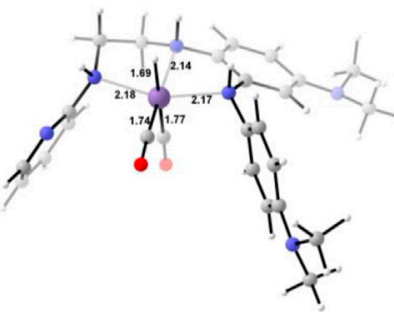

$3 c$

IN1 (3.0 $\mathrm{kcal} / \mathrm{mol})$

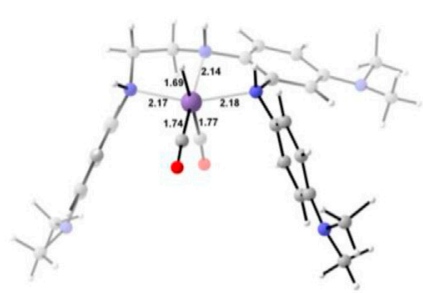

$\mathbf{3 b}$

IN1 (-2.4 $\mathrm{kcal} / \mathrm{mol})$

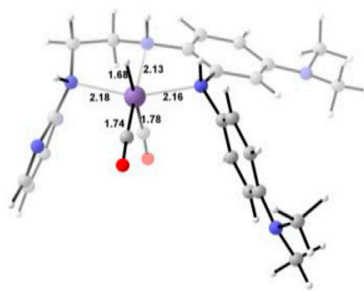

$3 d$

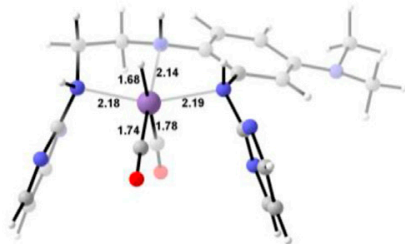

$3 \mathbf{e}$

IN1 (-2.9 kcal/mol)

FIGURE 10 |The optimized geometries of the Group $\mathbf{3}$ IN1 catalysts. The bond lengths are in $\AA$, and relative Gibbs free energies are in parentheses (The optimized geometries of all the transition states and intermediates are disclosed in Supplementary Data Sheet S1). 


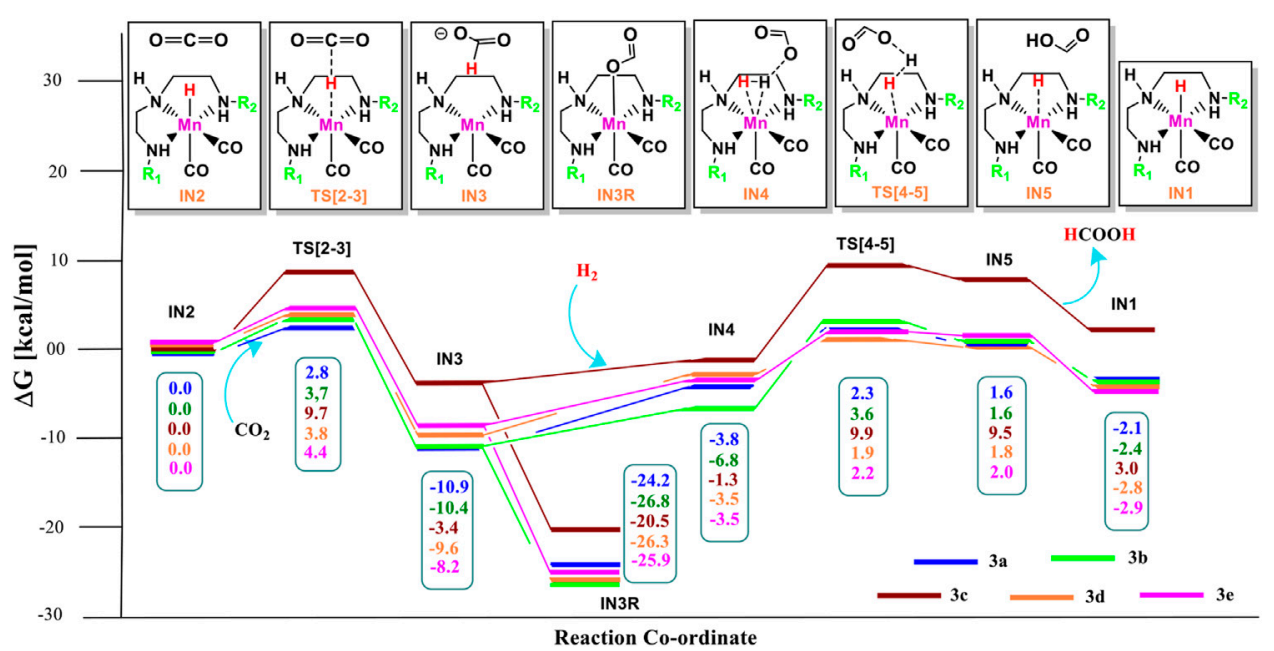

FIGURE 11 | Solvent-corrected relative Gibbs free energy profile for Mn(I)NNN-catalyzed formation of formic acid through the NC pathway for catalysts $\mathbf{3 a - 3 e . ~}$ Calculations were carried out at the M06/6-31G(d,p)-SDD(Mn), $\mathrm{SMD}\left(\mathrm{H}_{2} \mathrm{O}\right)$ level of theory.

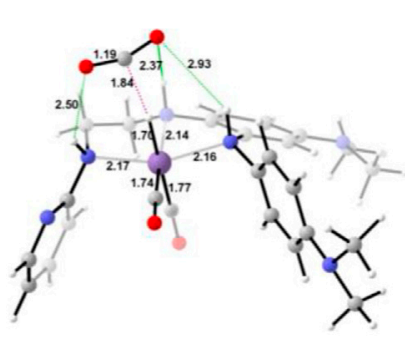

$3 c$

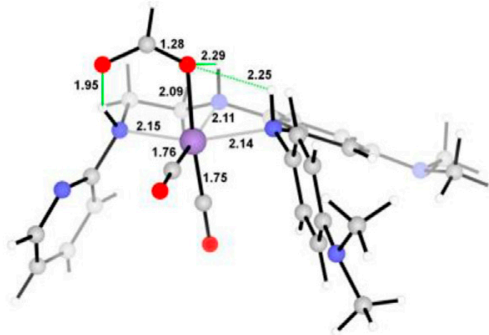

$3 c$

$\operatorname{TS}[2-3](9.7 \mathrm{kCal} / \mathrm{mol})$

IN3R (-20.47 kCal/mol)

FIGURE 12 | The optimized geometries of the transition states TS[2-3] in the formation of formic acid from carbon dioxide for catalysts $\mathbf{3 a - 3 e . ~ T h e ~ b o n d ~ l e n g t h s ~}$ are in $\AA$, and relative Gibbs free energies are in parentheses (The optimized geometries of all the transition states and intermediates are disclosed in Supplementary Data Sheet S1).

TABLE 3 | The catalytic performance of Group 3 catalyst, 3a-3e

\section{Catalyst group 3}

Activation energy $\left(\Delta \mathrm{G}^{\ddagger}\right)(\mathrm{kcal} / \mathrm{mol})$

$\begin{array}{ll}3 a & 24.4 \\ 3 b & 28.0 \\ 3 c & 33.4 \\ 3 d & 25.4 \\ 3 e & 25.3\end{array}$

relative Gibbs free energy of the TS[2-3] of all the catalysts is in the range of 3.0-4.0 kcal/mol except for catalyst $3 \mathrm{c}(9.7 \mathrm{kcal} / \mathrm{mol})$. The TS [2-3] $[\mathrm{N}(1) \mathrm{H} . . . \mathrm{OCHO}=2.9 \AA, \mathrm{N}(4) \mathrm{H} . . \mathrm{OCHO}=2.4 \AA$, and $\mathrm{N}(7)$ $\mathrm{H} . . \mathrm{OCHO}=2.5 \AA]$ and IN3R [N(1) H. .OCHO = $2.29 \AA, \mathrm{N}(4)$ $\mathrm{H} . . \mathrm{OCHO}=2.25 \AA$, and $\mathrm{N}(7) \quad \mathrm{H} . . \mathrm{OCHO}=1.95 \AA]$ show moderate $\mathrm{H}$-bonds in all the catalysts (Figure 12). After careful evaluation, it is observed that the IN1 of $\mathbf{3 c}$ has higher energy than the rest of the catalysts, and hence, the entire catalytic cycle, transitions states, and intermediates associated with this catalyst have higher relative Gibbs free energy than the other catalysts of Group 3. The formation of IN3 is found to be exergonic by $12.0-13.0 \mathrm{kcal} / \mathrm{mol}$ in all the catalysts of Group 3. The IN3 isomerizes to the resting state, IN3R. The relative Gibbs free energy of the resting state IN3R is in the range of -24.0 to $-27.0 \mathrm{kcal} / \mathrm{mol}$ except for catalyst $3 \mathrm{c}(-20.5 \mathrm{kcal} /$ $\mathrm{mol})$. The IN3R is the rate-controlling state in the entire catalytic conversion. The IN3R again isomerizes to IN3 to undergo further reaction to form product IN5. The dihydrogen molecule adds to the IN3 to give the intermediate IN4. The IN4 forms a classical $\sigma$-complex with an Mn center. Similar to Group 2, a strong $\mathrm{Mn}-\mathrm{H}_{2} \sigma$-complex is formed in IN4 of 3a, while the remaining catalysts show a distorted $\mathrm{Mn}-\mathrm{H}_{2} \sigma$-complex, where one $\mathrm{Mn}-\mathrm{H}_{\mathrm{a}}$ $\left(1.88 \AA\right.$ ) is longer than the other $\mathrm{Mn}-\mathrm{H}_{\mathrm{b}}(1.82 \AA$ ) bond (Structure in Supplementary Data Sheet S1). A strong polarization must have led to this distortion.

The IN4 of the $\mathbf{3 b}(-6.8 \mathrm{kcal} / \mathrm{mol})$ is the most stable, and $\mathbf{3 c}$ $(-1.3 \mathrm{kcal} / \mathrm{mol})$ is the least stable among all the catalysts of Group 3. The IN4 further converts to the IN5 through the transition state TS 


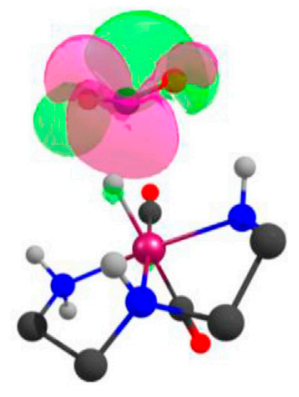

1a

TS[2-3] (13.53 kcal/mol)

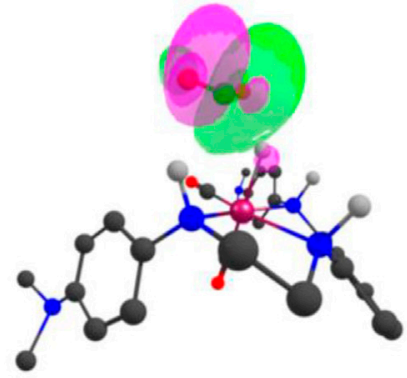

$2 b$

TS[2-3] (43.2 kcal $/ \mathrm{mol})$

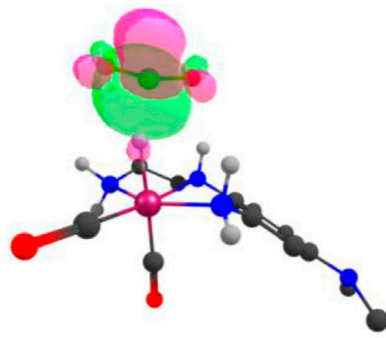

$3 \mathbf{a}$

TS[2-3] (33.09 kcal/mol)

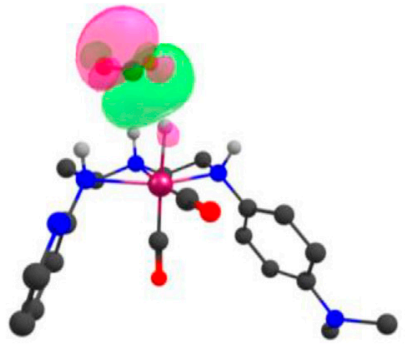

1c

TS[2-3] (36.7 kcal/mol)

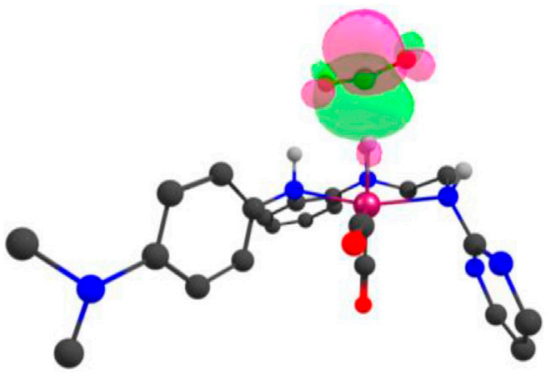

2d

TS[2-3] (34.98 kcal/mol)

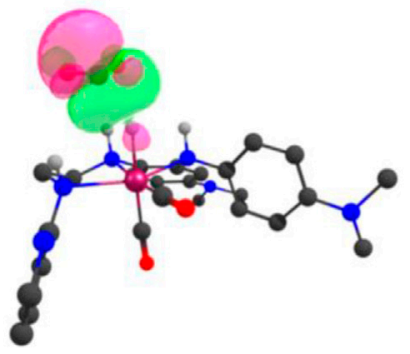

$3 c$

TS[2-3] (36.13 kcal/mol)

FIGURE 13 | (Mn) $\mathrm{H}-\mathrm{CO}_{2}$ interaction of natural bond orbitals (NBOs) of TS[2-3] of catalysts $\mathbf{1 a}, \mathbf{1 d}, \mathbf{1 e}, \mathbf{2 a}, \mathbf{2 b}, \mathbf{2 e}$, and $\mathbf{3 a}$ (isovalue = 0.0174). Interaction energies are indicated in parentheses. The structures are visualized using the Chemcraft software (Chemcraft, 2021) (NBO for all catalysts are given in Supplementary Data Sheet S1).

[4-5] with a maximum relative Gibbs free energy for catalyst $3 \mathrm{c}$ (9.9 kcal $/ \mathrm{mol})$ and minimum for catalyst $\mathbf{1 a}, \mathbf{1 d}$, and $\mathbf{1 e}(\sim 2.0 \mathrm{kcal} /$ mol). The entire $\mathrm{CO}_{2}$ hydrogenation is found to be thermodynamically favorable for all the catalysts except for catalyst 3c. This indicates that electron-donating and weakwithdrawing groups at an $\mathrm{Mn}$ center make dihydrogen polarization and catalyst generation sluggish. On the other hand, unsubstituted terminal nitrogen and terminal nitrogen with strong withdrawing groups facilitate the dihydrogen polarization and carbon dioxide to the formic acid formation (Table 3).

\section{NATURAL BOND ORBITAL}

Natural bond orbital (NBO) analysis is performed to gain a mechanistic insight into the carbon dioxide hydrogenation reaction mechanism (Chemcraft, 2021). The Lewis acid-base pair present in the chemical species can be predicted from the second-order perturbative estimation of donor-acceptor stabilization energy $\left(E_{s}\right)$. The NBO analysis of the transition states TS[2-3] provides the picture of relevant orbital interactions for the bond 


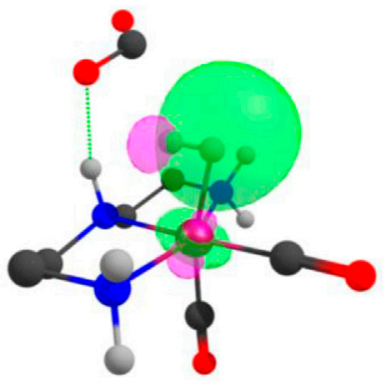

$1 \mathrm{a}$

TS[2-3] (53.6 kcal/mol)

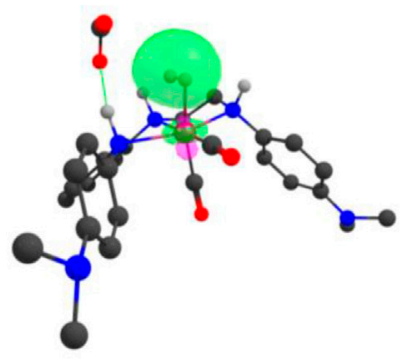

2b

TS[2-3] (69.3 kcal $/ \mathrm{mol})$

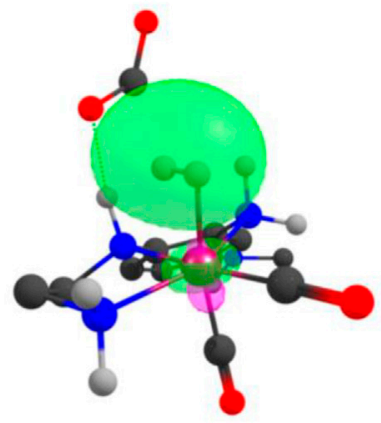

3a

TS[2-3] (65.8 kcal/mol)

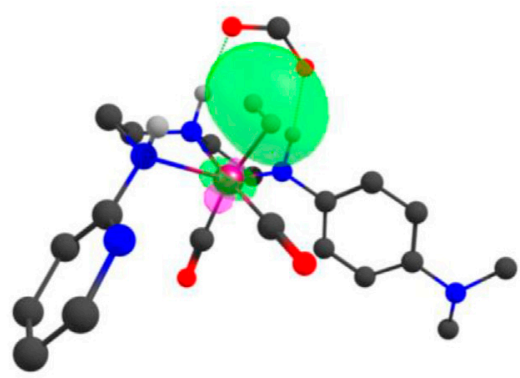

$1 \mathrm{c}$

TS[2-3] (64.8 $\mathrm{kcal} / \mathrm{mol})$

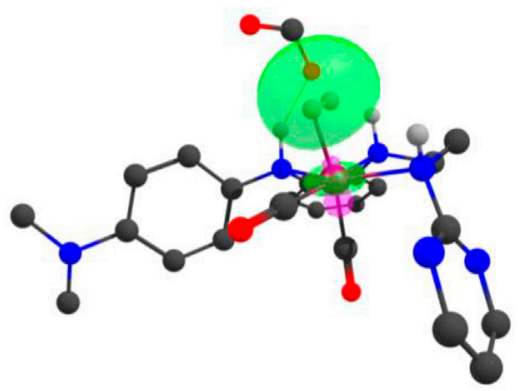

2d

TS[2-3] (69.4 kcal/mol)

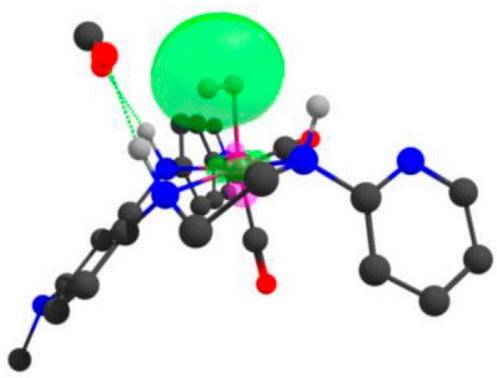

$3 c$

TS[2-3] (65.0 kcal/mol)

FIGURE $14 \mid \mathrm{Mn}-\mathrm{H}_{2}$ interaction NBOs of IN4 of catalysts $\mathbf{1 a}, \mathbf{1 d}, \mathbf{1 e}, \mathbf{2 a}, \mathbf{2} \mathbf{b}, \mathbf{2} \mathbf{e}$, and $\mathbf{3 a}$ (isovalue = 0.03). Interaction energies are indicated in parentheses. The structures are visualized using the Chemcraft software (Chemcraft, 2021) (NBO for all catalysts are given in Supplementary Data Sheet S1).

formation based on the second-order perturbative interaction energy. At the transition state TS[2-3], prominent bondforming interactions are observed for the $\mathrm{C}-\mathrm{H}(\mathrm{a})$ bond. (Figure 13).

Here, the TS[2-3] of 1e has stronger bond-forming interaction energy $(45.01 \mathrm{kcal} / \mathrm{mol})$ and lower relative Gibbs free energy $(3.0 \mathrm{kcal} / \mathrm{mol})$, whereas the TS[2-3] of 1a shows weaker bond-forming interaction energy of $(13.53 \mathrm{kcal} / \mathrm{mol})$ and higher relative Gibbs free energy $(4.8 \mathrm{kcal} / \mathrm{mol})$. A similar trend is observed when NBO analysis is performed for the IN4 of all the catalysts (Figure 14).

\section{CONCLUSION}

The structure-activity relationship study of computationally modeled $\mathrm{Mn}(\mathrm{I}) \mathrm{NNN}$ pincer complexes emphasize that the position and nature of the aromatic rings attached to the pincer ligands affect the catalytic performance to a considerable amount for carbon dioxide hydrogenation reaction. The Group $2 \mathrm{Mn}(\mathrm{I}) \mathrm{NNN}$ pincer complexes with benzene substituent at $\mathrm{C} 2-\mathrm{C} 3$ and identical substituents at both the terminal nitrogen are superior to all the catalysts from the three groups, whereas Group 1 catalysts without any aromatic substituents at $\mathrm{C} 2-\mathrm{C} 3$ show moderate catalytic 
performance, and Group 3 catalysts with N,N-dimethyl aniline at $\mathrm{C} 2-\mathrm{C} 3$ are sluggish toward carbon dioxide hydrogenation.

\section{DATA AVAILABILITY STATEMENT}

The original contributions presented in the study are included in the article/Supplementary Material. Further inquiries can be directed to the corresponding authors.

\section{AUTHOR CONTRIBUTIONS}

SP and VA conceived the project. SVP carried out the computational calculations and analysis of data. All authors were involved in the manuscript writing and revision. All authors have made substantial, direct and intellectual contributions to the work, and approved it for publication.

\section{REFERENCES}

Aleksandr, V. M., Christopher, J. C., and Truhlar, D. G. (2009). Universal Solvation Model Based on Solute Electron Density and on a Continuum Model of the Solvent Defined by the Bulk Dielectric Constant and Atomic Surface Tensions. J. Phys. Chem. B. 113, 6378-6396. doi:10.1021/jp810292n

Aleksandr, V. M., Christopher, J. C., and Truhlar, D. G. (2009). Universal Solvation Model Based on the Generalized Born Approximation with Asymmetric Descreening. J. Chem. Theor. Comput. 5, 2447-2464. doi:10.1021/ct900312z

Aresta, M. (2010). Carbon Dioxide Recovery and Utilization. Dordrecht: Kluwer Academic Publishers.

Balaraman, E., Gunanathan, C., Zhang, J., Shimon, L. J. W., and Milstein, D. (2011). Efficient Hydrogenation of Organic Carbonates, Carbamates and Formates Indicates Alternative Routes to Methanol Based on $\mathrm{CO}_{2}$ and CO. Nat. Chem. 3, 609-614. doi:10.1038/nchem.1089

Bernskoetter, W. H., and Hazari, N. (2017). Reversible Hydrogenation of Carbon Dioxide to Formic Acid and Methanol: Lewis Acid Enhancement of Base Metal Catalysts. Acc. Chem. Res. 50, 1049-1058. doi:10.1021/acs.accounts.7b00039

Bertini, F., Glatz, M., Gorgas, N., Stöger, B., Peruzzini, M., Veiros, L. F., et al. (2017). Veiros, Karl Kirchner and Luca GonsalviCarbon Dioxide Hydrogenation Catalysed by Well-Defined Mn(I) PNP Pincer Hydride Complexes. Chem. Sci. 8, 5024-5029. doi:10.1039/c7sc00209b

Bertini, F., Gorgas, N., Stöger, B., Peruzzini, M., Veiros, L. F., Kirchner, K., et al. (2016). Efficient and Mild Carbon Dioxide Hydrogenation to Formate Catalyzed by Fe(II) Hydrido Carbonyl Complexes Bearing 2,6-(Diaminopyridyl)diphosphine Pincer Ligands. ACS Catal. 6 (5), 2889-2893. doi:10.1021/acscatal.6b00416

Boodsarin, S., Wodrich, M. D., and Corminboeuf, C. (2018). Unraveling Metal/Pincer Ligand Effects in the Catalytic Hydrogenation of Carbon Dioxide to Formate. Organometallics 37 (24), 4568-4575. doi:10.1021/acs.organomet.8b00490

BP Statistical Review of World Energy (2019).BP Statistical Review of World Energy. 68th ed. London, United Kingdom: BPp.l.c.

Campos, J., Hintermair, U., Brewster, T. P., Takase, M. K., and Crabtree, R. H. (2014). Catalyst Activation by Loss of Cyclopentadienyl Ligands in Hydrogen Transfer Catalysis with CpIrIII Complexes. ACS Catal. 4 (3), 973-985. doi:10.1021/cs401138f

Carpenter, J. E., and Weinhold, F. (1988). Analysis of the Geometry of the Hydroxymethyl Radical by the "different Hybrids for Different Spins" Natural Bond Orbital Procedure. J. Mol. Struct. THEOCHEM. 169, 41-62. doi:10.1016/0166-1280(88)80248-3

Centi, G., and Perathoner, S. (2009). Opportunities and Prospects in the Chemical Recycling of Carbon Dioxide to Fuels. Catal. Today. 148, 191-205. doi:10.1016/ j.cattod.2009.07.075

Chemcraft (2021). Chemcraft - Graphical Software for Visualization of Quantum Chemistry Computations. Available at: https://www.chemcraftprog.com.

\section{FUNDING}

This research was supported by SERB-DST for the research grant under the IMPRINT II project (File no. IMP/2018/001208/EN).

\section{ACKNOWLEDGMENTS}

VA and SVP acknowledge the Department of Chemistry, SP College, Pune, DST-FIST, and Dr. TR Ingle research foundation for the infrastructure and facilities.

\section{SUPPLEMENTARY MATERIAL}

The Supplementary Material for this article can be found online at: https:/www.frontiersin.org/articles/10.3389/fchem.2021.778718/ full\#supplementary-material

Choi, J., and Lee, Y. (2020). Catalytic Hydrogenation of CO2 at a Structurally Rigidified Cobalt center. Inorg. Chem. Front. 7, 1845-1850. doi:10.1039/ c9qi01431d

Curley, J. B., Smith, N. E., Bernskoetter, W. H., Hazari, N., and Mercado, B. Q. (2018). Catalytic Formic Acid Dehydrogenation and CO2 Hydrogenation Using Iron PNRP Pincer Complexes with Isonitrile Ligands. Organometallics. 37 (21), 3846-3853. doi:10.1021/acs.organomet.8b00534

CYLview. (2020). Université de Sherbrooke. Available at: http://www.cylview.org.

Dörthe, M., Peter, S., Henrik, J., and Beller, M. (2016). Formic Acid as a Hydrogen Storage Material - Development of Homogeneous Catalysts for Selective Hydrogen Release. Chem. Soc. Rev. 45, 3954-3988. doi:10.1039/c5cs00618j

Foster, J. P., and Weinhold, F. (1980). Natural Hybrid Orbitals. J. Am. Chem. Soc. 102, 7211-7218. doi:10.1021/ja00544a007

Frisch, M. J., Trucks, G. W., Schlegel, H. B., Scuseria, G. E., Robb, M. A., Cheeseman, J. R., et al. (2016). Gaussian 16, Revision C.01. Wallingford C. $\mathrm{T}$ : Gaussian, Inc.

Fukui, K. (1970). Formulation of the Reaction Coordinate. J. Phys. Chem. 74, 4161-4163. doi:10.1021/j100717a029

Fukui, K. (1981). The Path of Chemical Reactions - the IRC Approach. Acc. Chem. Res. 14, 363-368. doi:10.1021/ar00072a001

Furstner, A. (2016). Iron Catalysis in Organic Synthesis: A Critical Assessment of what it Takes to Make This Base Metal a Multitasking Champion. ACS Cent. Sci. 2 (11), 778-789.

Ganesh, I. (2014). Conversion of Carbon Dioxide into Methanol - a Potential Liquid Fuel: Fundamental Challenges and Opportunities (A Review). Renew. Sustain. Energ. Rev. 31, 221-257. doi:10.1016/j.rser.2013.11.045

Garbe, M., Junge, K., and Beller, M. (2017). Homogeneous Catalysis by Manganese-Based Pincer Complexes. Eur. J. Org. Chem. 2017, 4344-4362. doi:10.1002/ejoc.201700376

Garbe, M., Wei, Z., Tannert, B., Spannenberg, A., Jiao, H., Bachmann, S., et al. (2019). Enantioselective Hydrogenation of Ketones Using Different Metal Complexes with a Chiral PNP Pincer Ligand. Adv. Synth. Catal. 361 (8), 1913-1920. doi:10.1002/adsc.201801511

Ge, H., Chen, X., and Yang, X. (2016). A Mechanistic Study and Computational Prediction of Iron, Cobalt and Manganese Cyclopentadienone Complexes for Hydrogenation of Carbon Dioxide. Chem. Commun. 52, 12422-12425. doi:10.1039/c6cc05069g

Glendening, E. D., Reed, A. E., Carpenter, J. E., and Weinhold, F. (1987). "Extension of Lewis Structure Concepts to Open-Shell and Excited-State Molecular Species," Ph.D. Thesis. (Madison, WI: University of Wisconsin).

Global Monitoring Division (2019). “Global Greenhouse Gas Reference NetworkTrends in Atmospheric Carbon Dioxide. National Oceanic and Atmospheric Administration," in Earth System Research Laboratory (Mauna Loa, Hawaii, U.S.December: U.S. Department of Commerce), 5. 
Hariharan, P. C., and Pople, J. A. (1973). The Influence of Polarization Functions on Molecular Orbital Hydrogenation Energies. Theoret. Chim. Acta. 28, 213-222. doi:10.1007/bf00533485

Hay, P. J., and Wadt, W. R. (1985). Ab Initio effective Core Potentials for Molecular Calculations. Potentials for $\mathrm{K}$ to Au Including the Outermost Core Orbitals. J. Chem. Phys. 82, 299-310. doi:10.1063/1.448975

Hehre, W. J., Ditchfield, R., and Pople, J. A. (1972). Self-Consistent Molecular Orbital Methods. XII. Further Extensions of Gaussian-type Basis Sets for Use in Molecular Orbital Studies of Organic Molecules. J. Chem. Phys. 56, 2257-2261. doi:10.1063/1.1677527

Huff, C. A., and Sanford, M. S. (2011). Cascade Catalysis for the Homogeneous Hydrogenation of CO2 to Methanol. J. Am. Chem. Soc. 133, 18122-18125. doi:10.1021/ja208760j

Irina, O., Tamm, T., Ahlquist, M. S. G., and Ahlquist, G. (2016). Reduced State of Iridium PCP Pincer Complexes in Electrochemical CO2 Hydrogenation. ACS Catal. 6 (6), 3834-3839. doi:10.1021/acscatal.6b01233

Jain, P., Pal, S., and Avasare, V. (2018). Ni(COD)2-Catalyzed Ipso-Silylation of 2Methoxynaphthalene: A Density Functional Theory Study. Organometallics. 37, 1141-1149. doi:10.1021/acs.organomet.8b00046

Jan, P., Eder, W., Stöger, B., Realista, S., Martinho, P. N., Calhorda, M. J., et al. (2020). Synthesis, Characterization, and Catalytic Reactivity of $\{\mathrm{CoNO}\} 8$ PCP Pincer Complexes. Organometallics 39 (14), 2594-2601. doi:10.1021/acs.organomet.0c00167

Jessica, D. C., Dekarske, J. R., McCulloch, B. J., and Ozerov, O. V. (2015). Cyclometallation of the NNN Pincer Ligand in Complexes of Platinum. Inorg. Chem. Front. 2, 912-916. doi:10.1039/c5qi00102a

Jessica, S. F., Wan, K. Y., Sues, P. E., and Morris, R. H. (2017). Ketone Asymmetric Hydrogenation Catalyzed by P-NH-P' Pincer Iron Catalysts: An Experimental and Computational Study. ACS Catal. 7 (1), 316-326. doi:10.1021/acscatal.6b02489

Jörg, E., and Huang, K.-W. (2017). Formic Acid as a Hydrogen Energy Carrier. ACS Energ. Lett. 2 (1), 188-195. doi:10.1021/acsenergylett.6b00574

Kar, S., Goeppert, A., Kothandaraman, J., and Prakash, G. K. S. (2017). ManganeseCatalyzed Sequential Hydrogenation of $\mathrm{CO} 2$ to Methanol via Formamide. ACS Catal. 7, 6347-6351. doi:10.1021/acscatal.7b02066

Kar, S., Rauch, M., Kumar, A., Leitus, G., Ben-David, Y., and Milstein, D. (2020). Selective Room-Temperature Hydrogenation of Amides to Amines and Alcohols Catalyzed by a Ruthenium Pincer Complex and Mechanistic Insight. ACS Catal. 10, 5511-5515. doi:10.1021/acscatal.0c01406

Kar, S., Sen, R., Kothandaraman, J., Goeppert, A., Chowdhury, R., Munoz, S. B., et al. (2019). Mechanistic Insights into Ruthenium-Pincer-Catalyzed AmineAssisted Homogeneous Hydrogenation of $\mathrm{CO} 2$ to Methanol. J. Am. Chem. Soc. 141 (7), 3160-3170. doi:10.1021/jacs.8b12763

Kassem, B., Thenert, K., Wiesenthal, J., Hoppe, C., and Klankermayer, J. (2020). Utilization of Formic Acid as C1 Building Block for the Ruthenium-Catalyzed Synthesis of Formaldehyde Surrogates. ChemCatChem 12 (7), 1944-1947. doi:10.1002/cctc.201902332

Kothandaraman, J., Goeppert, A., Czaun, M., Olah, G. A., and Prakash, G. K. S. (2016). Conversion of CO2 from Air into Methanol Using a Polyamine and a Homogeneous Ruthenium Catalyst. J. Am. Chem. Soc. 138, 778-781. doi:10.1021/jacs.5b12354

Kumar, A., Daw, P., Espinosa-Jalapa, N. A., Leitus, G., Shimon, L. J. W., Ben-David, Y., et al. (2019). CO2 Activation by Manganese Pincer Complexes through Different Modes of Metal-Ligand Cooperation. Dalton Trans. 48, 14580-14584. doi:10.1039/c9dt03088c

Langer, R., Diskin-Posner, Y., Leitus, G., Shimon, L. J. W., Ben-David, Y., and Milstein, D. (2011). Low-Pressure Hydrogenation of Carbon Dioxide Catalyzed by an Iron Pincer Complex Exhibiting Noble Metal Activity. Angew. Chem. Int. Ed. 50, 9948-9952. doi:10.1002/anie.201104542

Liu, P., Xu, X., Dong, X., Keitz, B. K., Herbert, M. B., Grubbs, R. H., et al. (2012). Z-selectivity in Olefin Metathesis with Chelated Ru Catalysts: Computational Studies of Mechanism and Selectivity. J. Am. Chem. Soc. 134, 1464-1467. doi:10.1021/ja2108728

Luca, P., Danielle, L., Justo, P., and Nielsen, M. (2020). Recent Progress with Pincer Transition Metal Catalysts for Sustainability. Catalysts 10 (7), 773. doi:10.3390/ catal10070773

Miriam, N., Mori, K., Salinas-Torres, D, Kuwahara, Y., and Yamashita, H. (2019). New Approaches toward the Hydrogen Production from Formic Acid Dehydrogenation over Pd-Based Heterogeneous Catalysts. Front. Mater. 6, 2296-8016. doi:10.3389/ fmats.2019.00044
Peris, E., and Crabtree, R. H. (2018). Key Factors in Pincer Ligand Design. Chem. Soc. Rev. 47, 1959-1968. doi:10.1039/c7cs00693d

Reed, A. E., Curtiss, L. A., and Weinhold, F. (1988). Intermolecular Interactions from a Natural Bond Orbital, Donor-Acceptor Viewpoint. Chem. Rev. 88, 899-926. doi:10.1021/cr00088a005

Reed, A. E., and Weinhold, F. (1985). Natural Localized Molecular Orbitals. J. Chem. Phys. 83, 1736-1740. doi:10.1063/1.449360

Reed, A. E., Weinstock, R. B., and Weinhold, F. (1985). Natural Population Analysis. J. Chem. Phys. 83, 735-746. doi:10.1063/1.449486

Smith, J. D., Chih, E., Piers, W. E., and Spasyuk, D. M. (2018). Tuning Iridium (I) PCcarbeneP Frameworks for Facile Cooperative N2O Reduction. Polyhedron 155, 281-290. doi:10.1016/j.poly.2018.08.054

Talukdar, K., Issa, A., and Jurss, J. W. (2019). Synthesis of a Redox-Active NNPtype Pincer Ligand and its Application to Electrocatalytic CO2 Reduction with First-Row Transition Metal Complexes. Front. Chem. 7 (330), 330-2646. doi:10.3389/fchem.2019.00330

Tang, S., von Wolff, N., Diskin-Posner, Y., Leitus, G., Ben-David, Y., and Milstein, D. (2019). Pyridine-Based PCP-Ruthenium Complexes: Unusual Structures and Metal-Ligand Cooperation. J. Am. Chem. Soc. 141, 7554-7561. doi:10.1021/ jacs.9b02669

Wang, W.-H., Muckerman, J. T., Fujita, E., and Himeda, Y. (2013). Mechanistic Insight through Factors Controlling Effective Hydrogenation of $\mathrm{CO} 2$ Catalyzed by Bioinspired Proton-Responsive Iridium(III) Complexes. ACS Catal. 3, 856-860. doi:10.1021/cs400172j

Wen, J., Wang, F., and Zhang, X. (2021). Asymmetric Hydrogenation Catalyzed by First-Row Transition Metal Complexes. Chem. Soc. Rev. 50, 3211-3237. doi:10.1039/d0cs00082e

Wesselbaum, S., Moha, V., Meuresch, M., Brosinski, S., Thenert, K. M., Kothe, J., et al. (2015). Hydrogenation of Carbon Dioxide to Methanol Using a Homogeneous Ruthenium-Triphos Catalyst: from Mechanistic Investigations to Multiphase Catalysis. Chem. Sci. 6, 693-704. doi:10.1039/c4sc02087a

Wesselbaum, S., vom Stein, T., Klankermayer, J., and Leitner, W. (2012). Hydrogenation of Carbon Dioxide to Methanol by Using a Homogeneous Ruthenium-Phosphine Catalyst. Angew. Chem. Int. Ed. 51, 7499-7502. doi:10.1002/anie.201202320

Zell, T., and Milstein, D. (2015). Hydrogenation and Dehydrogenation Iron Pincer Catalysts Capable of Metal-Ligand Cooperation by Aromatization/ Dearomatization. Acc. Chem. Res. 48, 1979-1994. doi:10.1021/acs.accounts.5b00027

Zhang, Y., MacIntosh, A. D., Wong, J. L., Bielinski, E. A., Williard, P. G., Mercado, B. Q., et al. (2015). Iron Catalyzed CO2hydrogenation to Formate Enhanced by Lewis Acid Co-catalysts. Chem. Sci. 6, 4291-4299. doi:10.1039/ c5sc01467k

Zhao, Y., and Truhlar, D. G. (2008a). Density Functionals with Broad Applicability in Chemistry. Acc. Chem. Res. 41, 157-167. doi:10.1021/ar700111a

Zhao, Y., and Truhlar, D. G. (2008b). The M06 Suite of Density Functionals for Main Group Thermochemistry, Thermochemical Kinetics, Noncovalent Interactions, Excited States, and Transition Elements: Two New Functionals and Systematic Testing of Four M06-Class Functionals and 12 Other Functionals. Theor. Chem. Account. 120, 215-241. doi:10.1007/s00214-007$0310-\mathrm{x}$

Conflict of Interest: The authors declare that the research was conducted in the absence of any commercial or financial relationships that could be construed as a potential conflict of interest.

Publisher's Note: All claims expressed in this article are solely those of the authors and do not necessarily represent those of their affiliated organizations, or those of the publisher, the editors, and the reviewers. Any product that may be evaluated in this article, or claim that may be made by its manufacturer, is not guaranteed or endorsed by the publisher.

Copyright (c) 2021 Parmar, Avasare and Pal. This is an open-access article distributed under the terms of the Creative Commons Attribution License (CC $B Y)$. The use, distribution or reproduction in other forums is permitted, provided the original author(s) and the copyright owner(s) are credited and that the original publication in this journal is cited, in accordance with accepted academic practice. No use, distribution or reproduction is permitted which does not comply with these terms. 